\title{
Use of spirometry and recording of smoking habits of COPD patients increased in primary health care during national COPD programme
}

\author{
Tuula Vasankari ${ }^{1,2^{*}}$, Anne Pietinalho ${ }^{1}$, Kalle Lertola ${ }^{3}$, Seppo YT Junnila ${ }^{4}$ and Kari Liippo ${ }^{1}$
}

\begin{abstract}
Background: In Finland, a national programme for COPD prevention and treatment was developed in 1998. The main goals of the programme were to diagnose COPD as early as possible and to encourage people to quit smoking. The role of primary health care was emphasized in the programme. Our aim was to investigate the use of spirometry and recording of smoking habits of COPD patients in primary health care before and during the COPD programme.
\end{abstract}

Methods: We compared patients with respiratory symptoms or diseases visiting primary health care during 1997 (before programme) and 2002 (during programme). Patients with respiratory symptoms were divided into two groups: COPD patients and "others". Patient records were thoroughly investigated and data retrieved from them.

Results: There was a significant increase in the whole study group from $8.0 \%$ to $38.9 \%$ in the use of spirometry ( $p<0.001$ ). This increase was significant both in the COPD group (from 32.0\% to 79.6\%, $p<0.001$ ) and "others" (from $5.6 \%$ to $32.8 \%, p<0.001$ ). Written information on smoking habits in patient records increased from $16.6 \%$ of all patients in 1997 to 53.2\% in 2002 ( $p<0.001$ ), and in COPD group from 45.0\% to 84.3\% ( $p<0.001$ ).

Conclusions: We observed a significant increase in the use of spirometry and knowledge of smoking habits in COPD patients, which may be a result of the Finnish national COPD programme.

Keywords: COPD, diagnosis, primary healthcare, respiratory symptoms, spirometry, smoking

\section{Background}

Chronic obstructive pulmonary disease (COPD) is a major health problem causing morbidity and mortality worldwide [1-3]. The incidence of COPD is increasing and its financial impact escalating [4]. International and national guidelines of COPD have been published recently to standardize in order to make the diagnosis and treatment of the disease equal in different settings [5-7].

COPD should be diagnosed using the appropriate measurements of lung function [8-11]. In the early stage of COPD airflow obstruction can be present without causing symptoms. Especially this group warrants an early diagnosis, and the role of primary healthcare physicians is crucial in this respect $[9,12]$. There are some reports

\footnotetext{
*Correspondence: tuula.vasankari@utu.fi

${ }^{1}$ Finnish Lung Health Association, Sibeliuksenkatu 11 A 1, Fl-00250 Helsinki Finland

Full list of author information is available at the end of the article
}

that indicate shortcomings of the detection of COPD in primary care such as underuse of spirometry, in its diagnosis [13-16]. Cigarette smoking is the major risk factor for the disease, and the importance of smoking cessation has been shown in preventing further decline of lung function [17]. Knowledge of patients smoking habits is essential both in diagnosis and treatment of COPD [18].

In Finland, the National Programme for Chronic Bronchitis and Chronic Obstructive Pulmonary Disease 1998-2007 was designed by The Finnish Lung Health Association (Filha, NGO) in cooperation with the Ministry of Social Affairs and Health and the Pulmonary Association Heli (NGO) with the help of a working group of experts. It was subsequently published on behalf of the Ministry of Social Affairs and Health in 1998 for 10 years [19]. The main goals of the programme were to diagnose COPD as early as possible and to encourage people to quit smoking. The role of
C Biomed Central

() 2011 Vasankari et al; licensee BioMed Central Ltd. This is an Open Access article distributed under the terms of the Creative Commons Attribution License (http://creativecommons.org/licenses/by/2.0), which permits unrestricted use, distribution, and reproduction in any medium, provided the original work is properly cited. 
primary health care in the diagnosis and treatment of COPD was emphasized in the programme. A nationwide implementation was performed in specialized as well as in primary health care, coordinated by Filha. At first, they were collaborating together with all [21] hospital districts (especially their pulmonary clinics) and all [6] occupational health districts to organize training events together with hospitals, and primary health care personnel were also invited. The topics were COPD as a disease, diagnosis of COPD (spirometry), smoking cessation and treatment of COPD. Secondly the training events were organized in collaboration with 156 (of 270) primary health care centers that were interested and willing to participate in this training. These sessions were arranged at health care stations during the working day (2-4 hours per time). All training was multidisciplinary. Approximately one third of the participants were doctors and two thirds nurses. From 1997 to 2002, approximately 210 training events for recognition of COPD were arranged around the country. As many as 8 200 health care professionals attended the meetings. Two information and training opportunities were offered to the personnel of each health care center during 5 years. The evidence-based Finnish Current Care Guidelines for COPD were introduced in 1999, and were also included in the implementation [20]. As far as we know there are no data concerning the effects of national programmes on diagnosis of COPD in primary health care.

The present study aimed to investigate the use of spirometry in diagnosis and follow-up of COPD patients and recording of smoking habits in a primary health care center before and during the national COPD programme.

\section{Methods}

A medium-sized primary healthcare center in south-west Finland with computerized patient records was chosen for the study. The healthcare center chosen used electronic patient record system for all patient data archiving. For every patient visit an International Classification of Primary Care (ICPC) code was recorded, and information concerning the cause of visit, clinical findings, results of examinations and treatment suggested was documented. Subjects were all aged $>16$ years to include all adults visiting primary health care due to respiratory symptoms. The year 1997 was chosen to represent the situation in the country before the introduction of the 1998 national programme and campaign for detecting and treating COPD, and the year 2002 to represent the impact of the programme.

The population living in the area of this healthcare center in 1997 was 44 402, of whom 36170 were aged > 16 years. The figures for 2002 were 46063 and 37 444, respectively. In 1997 and 2002, the number of doctor visits for all causes was 85,535 and 89,787 , respectively. For every visit a main diagnosis routinely documented by the treating physician to the healthcare center records was available for the study. All the visits due to respiratory symptoms or diseases were included in the study. Visits due to COPD were identified retrospectively with the help of ICPC (International classification of primary care) [21] and International Statistical Classification of Diseases and Related Health Problem (ICD10) codes recorded. ICPC codes were used almost solely, and ICD10 codes were used only during primary health care in-hospital periods. In-hospital and polyclinical treatment in specialized health care were not included in the study. The doctors responsible for diagnosing and treating patients did not know about the study when they met the patients. Our aim was to discover all new and prediagnosed COPD patients visiting primary health care during each study year. We also included codes of other obstructive respiratory diseases and symptoms suggestive of COPD to find those COPD cases remaining undiagnosed. The overall diagnostic efforts done due to suggestive respiratory symptoms by general practitioners were studied. The diagnosis codes included were those of chronic bronchitis, emphysema, COPD, asthma, cough, dyspnea, wheezing, abnormal sputum and bronchiectasis.

Based on medical record data, patients with respiratory symptoms were divided into two groups: COPD patients and "others". The COPD group was of primary interest. All the available data, including those before our study period, were used.

To be included in the COPD group a patient had to have:

- An earlier diagnosis of COPD made in specialized health care (respiratory clinic).' or

- A suitable history and deteriorated spirometric values. FEV1 had to be $\leq 80 \%$ of the predicted value and the FEV1/FVC ratio $\leq 80 \%$ according to Finnish clinical practice and guidelines $[19,22]$.

and

- Asthma excluded with peak expiratory (PEF) flow measurement data (those having repeatedly $\geq 20 \%$ of diurnal variation were excluded from the COPD group).

Other cases formed the group of "others" with respiratory symptoms. Some had asthma or other respiratory diseases, but most had only a variety of respiratory symptoms without specific diagnosis, or at least no diagnosis was made according to the data available.

Pack-years of smoking were computed for current and ex-smokers. One pack-year was regarded as equivalent to 20 cigarettes smoked daily for 1 year. The variables 
studied included sex, age, history of smoking, PEF and spirometric values.

The main outcomes of the study were the frequency of the use of spirometry for the diagnosis of respiratory symptoms suggestive of COPD and the adequate recording of smoking habits of those seeking medical advice due to their respiratory symptoms.

The statistical analysis was carried out using SPSS and SAS software. Categorical variables were tested by chisquared test, numerical variables by analysis of variance.

The study was approved by the Salo Healthcare Center Ethical Committee and was performed in accordance with the principles of the Declaration of Helsinki.

\section{Results}

In 1997 and 2002 a total of 1072 and 1645 patients with respiratory symptoms were included, respectively. The share of men was $38.3 \%$ (411) in 1997 and $37.0 \%$ (609) in 2002 (Table 1).

The diagnosis of COPD had been made in 100 cases in 1997 and in 216 cases in 2002, or medical record data made it possible to confirm COPD and exclude asthma by the study team. These cases were included in the COPD group. The remaining 972 patients in 1997 and 1 429 in 2002 formed the group "others". In 1997332 (34.2\%) of others had asthma, 7 (0.7\%) had chronic bronchitis and the reminder, 633 (65.1\%), of that group were without any specific diagnosis. The figures for 2002 were $443(31.0 \%), 26(1.8 \%)$ and $960(67.2 \%)$ respectively. The demographic details of the groups are shown in Table 1.

Altogether 29.6 patients per 1000 persons visited primary healthcare for respiratory symptoms in 1997, the respective figure was 43.9 per 1000 in 2002. The number of patients visiting primary health care due to COPD was 2.4 per 1000 persons in 1997 and 5.8 per 1000 in 2002.

There was a significant increase in the whole study group from $8.0 \%$ to $38.9 \%$ ( $<<0.001)$ in the use of spirometry in primary health care. This increase was significant ( $\mathrm{p}<0.001$ ) both in the COPD group (from $32.0 \%$ to $79.6 \%$ ) and "others" (from $5.6 \%$ to $32.8 \%$ ) (Table 1).

Written information on smoking habits in patient records increased significantly from $16.6 \%$ of all patients in 1997 to $53.2 \%$ in 2002 ( $\mathrm{p}<0.001$ ). Such information was obtained for $45.0 \%$ of patients in the COPD group in 1997, and significantly more often in $84.3 \%$ in 2002 (p < 0.001) (Table 1).

\section{Discussion}

According to our study, there was a clear increase in the use of spirometry in COPD patients as well as in all patients with respiratory symptoms during the 5 -year period after the introduction of the COPD programme in 1997, but also Finnish asthma programme 1994-2004 [23] and evidence-based current care guidelines for
COPD in 1999 [20] may partly explain this. Written information of the smoking habits of patients was more routinely performed in 2002 compared with the year 1997 both concerning all patients with respiratory symptoms and COPD patients.

The study site was chosen because of the availability of electronic patient records, which were quite rare in Finland at the beginning of the study. It is possible that this particular health care center was more progressive than most other primary health care centers concerning implementing new guidelines. The role of specialized health care for the improvement noticed could not be assessed in this study, but it could have had a role in that. An increase in the visits due to respiratory symptoms from 1997 to 2002 was obvious and could have been partly caused by increasing public knowledge concerning COPD and respiratory diseases. Despite of that the number of COPD patients visiting primary health care was on a lower level than expected in both study years. In a recent study the prevalence of COPD was $4.3 \%$ in men and $3.1 \%$ in women in Finland [24]. Compared with this, numerous undiagnosed patients with COPD probably existed in our study population, or they did not visit primary health care. Only one diagnosis code was routinely recorded on every visit, and with this study method we were not able to find those visits including COPD as other than primary cause of visit. Some of the patients could have been followed in specialized health care; we were not able to locate them in our study. On the other hand, the Finnish diagnostic criteria for COPD $[19,22]$ were introduced before GOLD criteria were set, and the cutoff point used for FEV1/FVC was higher than in GOLD causing a possibility of overdiagnosis of COPD.

A worrying figure was that only $8.0 \%$ of the patients had been examined by spirometry in 1997. This is in concordance with earlier studies $[9,25]$, but far less than that $(52 \%)$ in a new study from Sweden [26]. PEF follow-up was even less common. Without these two investigations, it was not possible to judge whether patients had COPD or asthma. After implementation of the national COPD programme the use of spirometry improved significantly in 2002. Despite being crucial in the diagnostic process of $\mathrm{COPD}$, knowledge of deteriorated lung function affects the success of smoking cessation attemps as a part of a motivational package $[27,28]$. Partly due to COPD programme as well as for other reasons including a national asthma programme launched before COPD programme the training of primary health care professionals concerning COPD was improved at the same time. There were some technical improvements in the recording of spirometry data in electronic patient records in the study period, which may have partly improved the situation from 1997 to 2002.

The entire study group consisted of patients with respiratory symptoms, but in 1997 , only $16.6 \%$ had 
Table 1 Characteristics of the study patients, knowledge of their smoking habits, and use of spirometry in the study groups, years 1997 and 2002

\begin{tabular}{|c|c|c|c|c|}
\hline & Group & 1997 & 2002 & $p$ \\
\hline \multirow[t]{3}{*}{ N } & COPD & 100 & 216 & $N A^{1}$ \\
\hline & Others & 972 & 1429 & NA \\
\hline & All & 1072 & 1645 & NA \\
\hline \multirow[t]{3}{*}{ Mean age (years $\pm S D$ ) } & COPD & $70.1(11.3)$ & $68.3(13.0)$ & 0.22 \\
\hline & Others & $51.7(19.8)$ & $53.4(19.3)$ & 0.03 \\
\hline & All & 53.4 & 55.4 & 0.96 \\
\hline \multirow{3}{*}{$\begin{array}{l}\text { Gender/male } \\
N(\%)\end{array}$} & COPD & $69(69.0)$ & $146(67.6)$ & 0.46 \\
\hline & Others & $342(35.2)$ & $463(32.4)$ & 0.09 \\
\hline & All & $411(38.3)$ & $609(37.0)$ & 0.49 \\
\hline \multirow[t]{3}{*}{ PEF } & COPD & $173.0(260.3)$ & $309.3(148.4)$ & 0.001 \\
\hline & Others & $263.3(227.1)$ & $414.8(121.0)$ & $<0.001$ \\
\hline & All & $247.1(235.0)$ & $390.8(135.0)$ & $<0.001$ \\
\hline \multirow[t]{3}{*}{ FEV1/FVC } & COPD & $61.9(10.6)$ & $67.4(14.0)$ & 0.04 \\
\hline & Others & $81.8(6.4)$ & $86.1(18.1)$ & 0.10 \\
\hline & All & $74.2(12.7)$ & $81.1(19.0)$ & 0.001 \\
\hline \multirow[t]{3}{*}{ Data on smoking status available N (\%) } & COPD & $45(45.0)$ & $182(84.3)$ & $<0.001$ \\
\hline & Others & $133(13.7)$ & $693(48.5)$ & $<0.001$ \\
\hline & All & $178(16.6)$ & $875(53.2)$ & $<0.001$ \\
\hline \multirow[t]{3}{*}{ Pack years of smoking } & COPD & $31.0(9.8)$ & 46.9 (17.9) & 0.03 \\
\hline & Others & $25.9(9.3)$ & $24.5(18.8)$ & 0.86 \\
\hline & All & $27.2(11.5)$ & $37.3(19.2)$ & 0.03 \\
\hline \multirow[t]{3}{*}{ Spirometry performed N (\%) } & COPD & $32(32.0)$ & $172(79.6)$ & $<0.001$ \\
\hline & Others & $54(5.6)$ & $468(32.8)$ & $<0.001$ \\
\hline & All & $86(8.0)$ & $640(38.9)$ & $<0.001$ \\
\hline
\end{tabular}

${ }^{1}$ Not available

smoking habits asked and recorded. Smoking is by far the biggest risk factor for COPD, and if ignored the disease will often remain undiagnosed. This situation improved greatly in 2002 when about half the patients were correctly asked about smoking and the data were recorded in patient records. During the study period, more attention was paid to anti-smoking work and corresponding legislation on the national level, which could have had a role in the improvement noticed. When patients admitted smoking, however the duration and heaviness of smoking was not always properly recorded. The total amount of cigarettes smoked in pack-years is important knowledge when estimating the harmful effects of smoking as well as when aiming to quit smoking [29].

\section{Conclusion}

A great increase in the use of spirometry and knowledge of smoking habits of COPD patients was seen in this specific health care center. A positive impact of the national programme for detection of obstructive pulmonary disease can partly explain this, but also other improvements in the national level as well as in this particular healthcare center may have had a synergistic effect on the approach. Whether this can be generalized to other countries should be studied in the future, and it would be optimal that future national programs will include monitoring systems included in the programs.

\section{Author details}

'Finnish Lung Health Association, Sibeliuksenkatu 11 A 1, Fl-00250 Helsinki Finland. '2Department of Respiratory Medicine, Turku University Hospital, Paimio Hospital, Alvar Aallon tie 275, Fl-21540 Preitilä Finland. ${ }^{3}$ Turku University, Fl-20014 Turun Yliopisto, Finland. ${ }^{4}$ Salo Healthcare Center, Sairaalantie 9, FI-24130 Salo, Finland.

\section{Authors' contributions}

TV participated in the design of the study, collected the data and drafted the manuscript. AP conceived of the study and participated in the design of the study. KLe performed the statistical analysis. SYTJ drafted the manuscript. KLi participated in the design of the study. All authors read and approved the final manuscript.

\section{Competing interests}

The authors declare that they have no competing interests. 
Received: 7 February 2011 Accepted: 21 September 2011

Published: 21 September 2011

\section{References}

1. Anto $J M$, Vermeire $P$, Vestbo J, Sunyer J: Epidemiology of chronic obstructive pulmonary disease. Eur Respir J 2001, 17:982-994.

2. Pauwels RA, Rabe KF: Burden and clinical features of chronic obstructive pulmonary disease (COPD). Lancet 2004, 364:613-620.

3. Lopez AD, Shibuya K, Rao C, Mathers CD, Hansell AL, Held LS, Schmid V, Buist S: Chronic obstructive pulmonary disease: current burden and future projections. Eur Respir J 2006, 27:397-412.

4. Hurd S: The impact of COPD on lung health worldwide. Epidemiology and incidence. Chest 2000, 117:15-4S.

5. From the Global Strategy for the Diagnosis, Management and Prevention of COPD, Global Initiative for Chronic Obstructive Lung Disease (GOLD) 2010. [http://www.goldcopd.org/], (accessed September, 2011).

6. National Institute for Clinical Excellence: Chronic obstructive pulmonary disease, Management of chronic obstructive pulmonary disease in adults in primary and secondary care. Clinical Guideline 12 London: NICE; 2000.

7. National Board of Health and Welfare: The National Board of Health and Welfare Guidelines for Asthma and COPD 2004 (in Swedish). Stockholm, Sweden: Socialstyrelsen; 2004

8. Ferguson GT, Enright PL, Buist AS, Higgins MW: Office spirometry for lung health assessment in adults: a consensus statement from the National Lung Health Education Programme. Respir Care 2000, 45:513-30.

9. van Schayck CP, Chavannes NH: Detection of asthma and chronic obstructive pulmonary disease in primary care. Eur Respir J 2003, 21(Suppl 39):16s-22s.

10. Bellamy D, Bouchard J, Henrichsen S, Johansson G, Langhammer A, Reid J, van Weel C, Buist S: International Primary Care Respiratory Group (IPCRG) Guidelines: management of chronic obstructive pulmonary disease (COPD). Prim Care Respir J 2006, 15:48-57.

11. Derom E, Weel C, Liistro G, Buffels J, Schermer T, Lammerse E, Wouters E, Decramer M: Primary care spirometry. Eur Respir J 2008, 31:197-203.

12. Voelkel NF: Raising awareness of COPD in primary care. Chest 2000, 117:372S-375S.

13. Chapman KR, Tashkin DP, Pye DJ: Gender bias in the diagnosis of COPD. Chest 2001, 119:1691-1695.

14. Weidinger $P$, Nilsson $\mathrm{J} L$, Lindblad U: Adherence to diagnostic guidelines and quality indicators in asthma and COPD in Swedish primary care. Pharmacoepidemiol Drug Saf 2009, 18(5):393-400.

15. Carlfjord S, Lindberg M: Asthma and COPD in primary health care, quality according to national guidelines: a cross-sectional and a retrospective study. BMC Family Practice 2008, 9:36.

16. Thorn J, Norrhall M, Larsson R, Curiac D, Axelsson G, Ammon C, Månsson J, Brisman J, Söderström AL, Björkelund C: Management of chronic obstructive pulmonary disease (COPD) in primary care: a questionnaire survey in western Sweden. Prim Care Respir J 2008, 17:26-31.

17. Anthonisen NR, Connett JE, Kiley JP, Altose MD, Bailey WC, Buist AS, Conway WA Jr, Enright PL, Kanner RE, O'Hara P: Effects of smoking intervention and the use of an inhaled anticholinergic bronchodilator on the rate of decline of FEV1: the Lung Health Study. JAMA 1994, 272:1497-1505.

18. Todd DC, Mclvor RA, Pugsley SO, Cox G: Approach to chronic obstructive pulmonary disease in primary care. Can Fam Physician 2008, 54:706-711.

19. Laitinen $L A$, Koskela $K$, the expert group listed in the foreword: Chronic bronchitis and chronic obstructive pulmonary disease: Finnish national guidelines for prevention and treatment 1998-2007. Respir Med 1999, 93:297-332.

20. COPD (online). Current Care (in Finnish). Working group set up by the Finnish Medical Society Duodecim and the Finnish Respiratory Society. Helsinki: The Finnish Medical Society Duodecim; 1999 [http://www. kaypahoito fil, (updated on 1 March 2004)

21. International Classifi cation of Primary Care ICPC-2 First Edition. WONCA International Classification Committee Oxford University Press Inc., New York. Wonca; 1987.

22. Sovijärvi A, Piirilä P, Korhonen O, Louhiluoto E, Pekkanen L: Spirometry and PEF-measurements; performance and assessment (in Finnish). Helsinki. Moodi 1997
23. Haahtela T, Laitinen LA: Asthma programme in Finland 1994-2004. Report of a Working Group. Clin Exp Allergy 1996, 26(Suppl 1):1-24.

24. Vasankari T, Impivaara O, Heliövaara M, Heistaro S, Liippo K, Puukka P, Saarelainen S, Kanervisto M, Jousilahti P: No increase in the prevalence of COPD in two decades. Eur Resp J 2010, 36:766-773.

25. Tirimanna PRS, van Schayck CP, den Otter JJ, van Weel C, van Herwaarden CLA, van den Boom, van Grunsven PM, van den Bosch WJ: Prevalence of asthma and COPD in general practice in 1992: has it changed since 1977? Br J Gen Pract 1996, 46:277-281.

26. Löfdahl CG, Tilling B, Ekström $T$, Jörgensen $L$, Johansson $G$, Larsson $K$ : COPD health care in Sweden-A study in primary and secondary care. Respir Med 2009, 104:404-11.

27. Rissler NL, Belcher DW: Adding spirometry, carbon-monoxide, and pulmonary symptom results to smoking cessation counceling-a randomized trial. JGIM 1990, 5:16-22.

28. Humerfelt S, Eide G, Aaro L, Gulsvik A: Effectivenes of postal smoking cessation advice: a randomised controlled trial in young men with reduced FEV1 and asbestos exposure. Eur Respir J 1998, 11:284-290.

29. West R, McNeill A, Raw M: Smoking cessation guidelines for health professionals: an update. Thorax 2000, 55:987-999.

\section{Pre-publication history}

The pre-publication history for this paper can be accessed here: http://www.biomedcentral.com/1471-2296/12/97/prepub

doi:10.1186/1471-2296-12-97

Cite this article as: Vasankari et al:: Use of spirometry and recording of smoking habits of COPD patients increased in primary health care during national COPD programme. BMC Family Practice 2011 12:97.

\section{Submit your next manuscript to BioMed Central and take full advantage of:}

- Convenient online submission

- Thorough peer review

- No space constraints or color figure charges

- Immediate publication on acceptance

- Inclusion in PubMed, CAS, Scopus and Google Scholar

- Research which is freely available for redistribution

Submit your manuscript at www.biomedcentral.com/submit
C Biomed Central 